\title{
An Alternative Method to the West African Compaction (WAC) Test Procedure
}

\author{
Meissa Fall ${ }^{1}$, Seydou Ba ${ }^{2}$, Déthiè Sarr ${ }^{1}$, Makhaly $\mathrm{Ba}^{1}$, Mapathé Ndiaye ${ }^{1}$ \\ ${ }^{1}$ Laboratoire de Mécanique et Modélisation, UFR Sciences de l'Ingénieur, Université de Thiès, Sénégal \\ ${ }^{2}$ Département de Géologie, Université Cheikh Anta Diop de Dakar, Sénégal \\ E-mail: meissa.fall@univ-thies.sn \\ Received April 22, 2011; revised June 3, 2011; accepted June 28, 2011
}

\begin{abstract}
It had been suggested to use the West African Compaction Test Procedure since the early 1950's so as to determine the CBR of gravel lateritic soils in West African countries [1]. This test procedure called West African Compaction (WAC) [2] is largely used in road construction in West African countries and had the particularity to be long and use a large amount of material. This note is the result of several comparisons between test procedures taken to determine the CBR from the WAC method to the standardized laboratory test commonly used to determine the CBR.
\end{abstract}

Keywords: West African Compaction Test Procedure, Compaction, Proctor, Gravel, Lateritic Soils, AASHTO

\section{Introduction}

The soils considered in this study were collected from different locations within Senegal. Standard laboratory tests were conducted to classify these soils and determine their properties. Laboratory testing consisted of particle size analysis (mechanical sieving and hydrometer analysis), specific gravity, consistency limits, and Modified Proctor compaction test (Figure 1 and Table 1). Laboratory tests were conducted on the investigated soils following the standard procedures of the American Society for Testing and Materials (ASTM). The Modified Proctor compaction test was conducted using the AASHTO T 99 procedure [3]. Test results showed that the selected soils are classified mainly as A-26 materials according to AASHTO. The CBR tests have to be determining under these different compaction efforts (10, 25, 55 blows). The value of the CBR at $95 \%$ of the OMP is graphically obtained by determining the value of the CBR at $95 \%$ OMP (Figure 2). The standardized method as related by the AASHTO T 193 [4] standard method of test procedure consist of determining the value of the CBR at the optimum of the compaction characteristics $\left(\gamma_{\text {dmax }}, W_{\text {opt. }}\right)$ (Figure 3). This test method provides for the determination of the CBR of a material at optimum water content or a range of water content from a specified compaction test

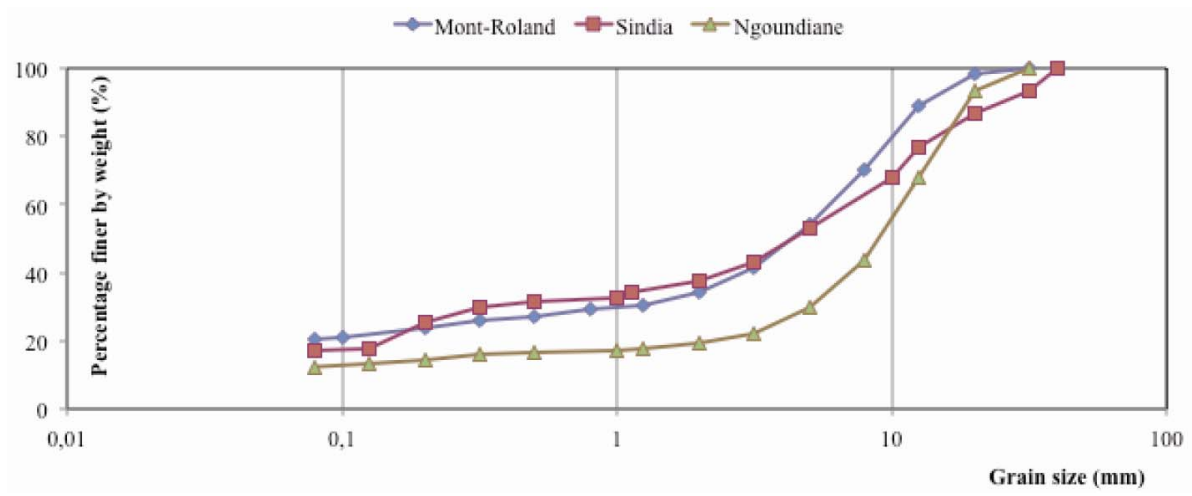

Figure 1. Grain size distribution of the gravel lateritic soils. 
Table 1. The lateritic soil characteristics.

\begin{tabular}{|c|c|c|c|c|c|c|c|}
\hline & $W l(\%)$ & $W p(\%)$ & $I p(\%)$ & $\gamma_{s}\left(k N / m^{3}\right)$ & AASHTO & $\gamma_{d} \max$ at $O M P\left(\mathrm{kN} / \mathrm{m}^{3}\right)$ & $W_{\text {opt. }}(\%)$ \\
\hline Sindia & 35 & 18 & 17 & 28.3 & A 2-6 & 19.5 & 10,5 \\
\hline Ngoundiane & 53 & 26 & 27 & 27.1 & A $2-6$ & 19.22 & 11 \\
\hline Mont-Rolland & 46 & 20 & 26 & 27.6 & A $2-6$ & 19.6 & 12.25 \\
\hline
\end{tabular}

Table 2. CBR values from the two procedures and from different time of wetting.

\begin{tabular}{|c|c|c|c|c|c|c|c|c|c|c|}
\hline & \multicolumn{5}{|c|}{ West African Compaction (WAC) } & \multirow{2}{*}{\multicolumn{5}{|c|}{$C B R$ at the optimum value of the water content }} \\
\hline & \multicolumn{5}{|c|}{ Values of the CBR at $95 \%$ OMP in function of the time of immersion } & & & & & \\
\hline & $0 \mathrm{~h}$ & $24 \mathrm{~h}$ & $48 \mathrm{~h}$ & $72 \mathrm{~h}$ & $96 \mathrm{~h}$ & $0 \mathrm{~h}$ & $24 \mathrm{~h}$ & $48 \mathrm{~h}$ & $72 \mathrm{~h}$ & $96 \mathrm{~h}$ \\
\hline Sindia & 139.9 & 83.2 & 57 & 45.3 & 40 & 142 & 85 & 62 & 47 & 42 \\
\hline Mont-Rolland & 185 & 167.9 & 146.8 & 122 & 120.2 & 189 & 172 & 150 & 124 & 123 \\
\hline
\end{tabular}

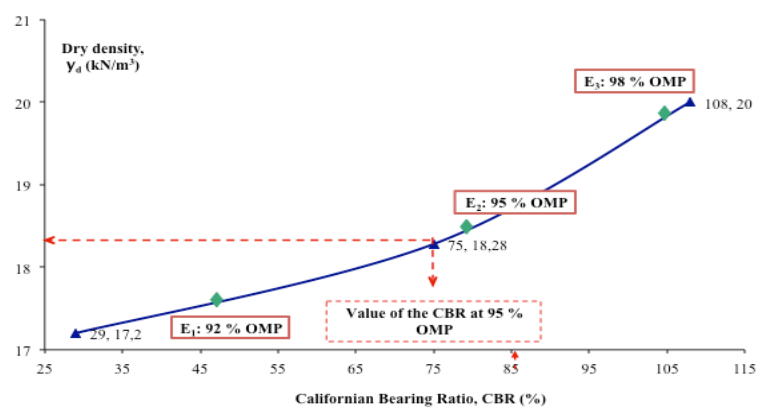

Figure 2. An example of the West African Compaction (WAC) method of determination of the CBR.

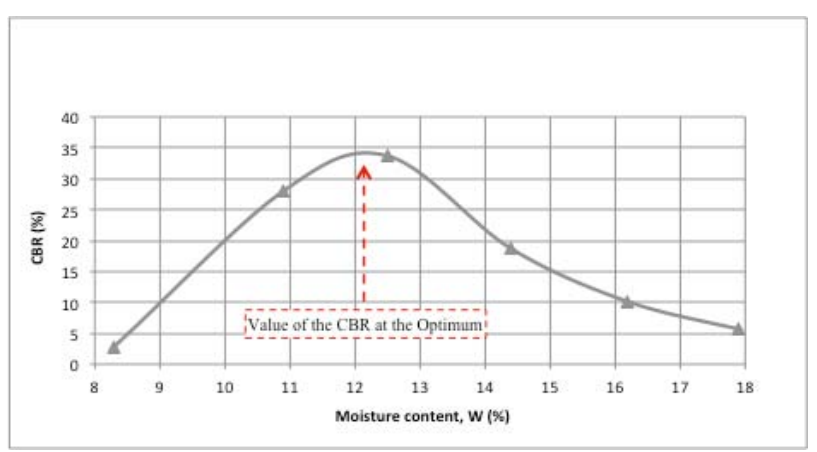

Figure 3. The CBR obtained from the Optimum of the Moisture content (the standardized method).

and a specified dry unit mass.

In the WAC test Procedure [1,2,5,6], each sample has to be wetted for 4 days and compacted with the required Proctor Energy $\left(E_{1}, E_{2}\right.$ and $\left.E_{3}\right)$. The engineering value of the CBR is obtained from the correspondence between the dry density at $95 \%$ OMP plotted to the experimental curve and directly read in the CBR axis. It's mainly a non-linear interpolation. Note that, the energies of compaction are below:

- Proctor Energy $E_{3}$

(55 blows of the Modified Proctor hammer),

- Proctor Energy $E_{2}$

(25 blows of the Modified Proctor hammer);

\section{- Proctor Energy $\mathrm{E}_{1}$}

(10 blows of the Modified Proctor hammer).

In the Classical CBR Determination, each sample wetted for 4 days represent the CBR value for each point determined for the compaction curve. The Energy of Compaction remains the same (Modified Proctor: 55 blows for 5 layers). The engineering value of the CBR is obtained from the Optimum of the Water Content. The CBR test procedure stills the same for each sample.

\section{Comparison between CBR Values}

On Figures 4, 5 and 6 we represented the variations of the CBR according to the moisture content. They represent the evolution of the soil for various water contents considered to establish the Proctor curve of each lateritic soil with the modified Proctor energy (55 blows). This classical procedure is different from the traditional West African method, which is usually carried out in the African geotechnical laboratories where CBR test is carried out with various compactions energies $(10,25$ and 55 blows) and with a time of immersion of 96 hours. These figures show that these three materials are sensitive to water; indeed the more the materials last in water the more their CBR lowers. The comparison of the CBR values determined after 96 hours of immersion for each of the three lateritic soils with that of the traditional

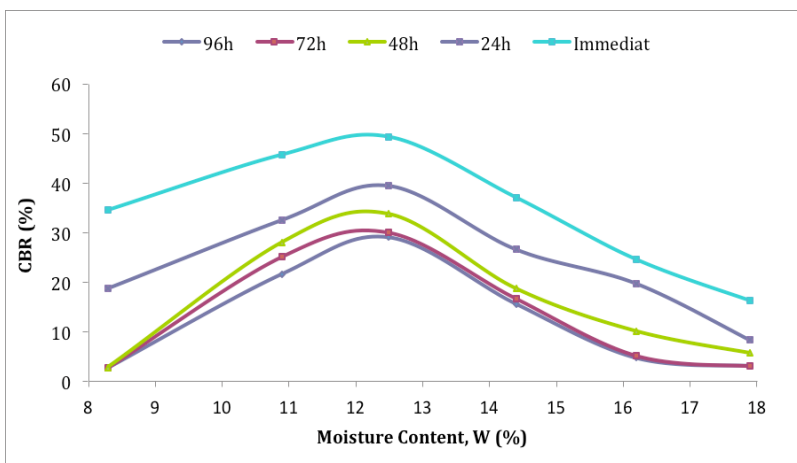

Figure 4. CBR versus moisture content according to time of immersion (Ngoundiane). 


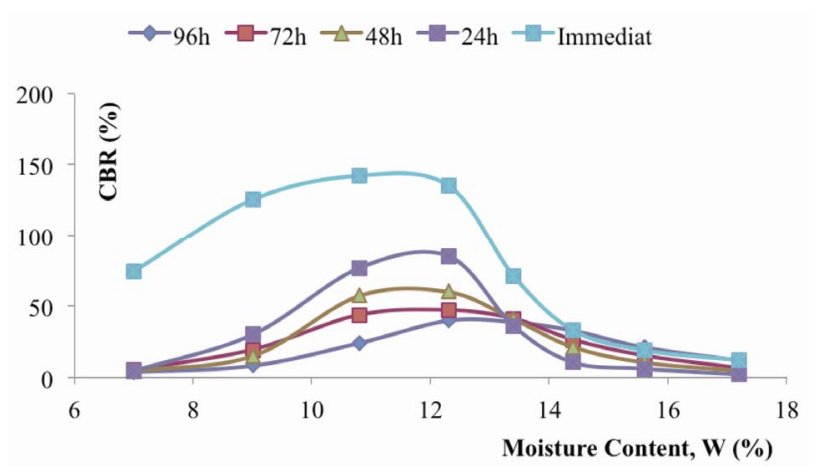

Figure 5. CBR versus moisture content according to time of immersion (Sindia).

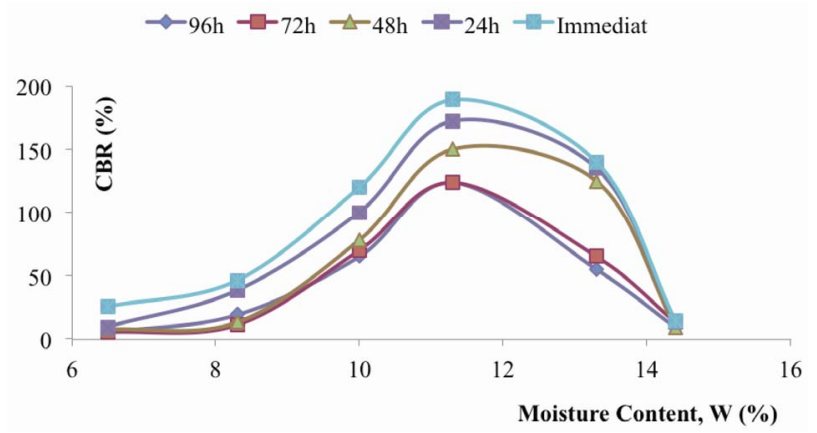

Figure 6. CBR versus moisture content according to time of immersion (Mont-Rolland).

of the three lateritic soils with that of the traditional method shows that we have almost similar values (Table 1) with differences in CBR ranging between 2 and 4: this proves that we can otherwise determine the CBR than by the traditional method.

Figure 7 represents the variation of CBR according to the time of immersion. According to these figures we note that the CBR is sensitive to water. While passing from the immediate condition ( 0 day) to an immersion condition (1, 2, 3 and 4 days), the CBR decreases considerably. This fall of CBR is most important for the first

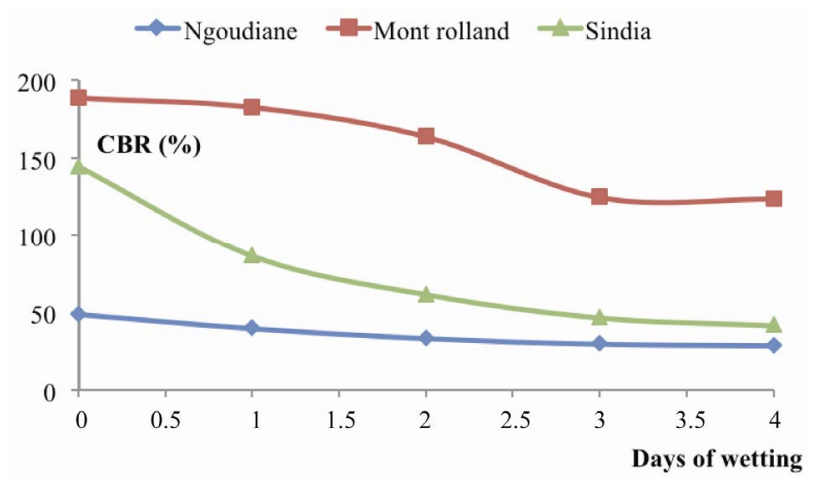

Figure 7. Evolution of the CBR with the days of immersion. three days, and then the CBR evolves in a stagnant way between the third and the fourth day. This lets think that saturation is reached at the third day. Ackroyd [5] finds that under the semi arid weather conditions, a period between 24 hours and 48 hours of immersion seems sufficient.

\section{Conclusions}

In Senegal and in the most West African countries, the determination of the CBR is done with the WAC method [6]. This method consists in determining the CBR index to $95 \%$ of the OMP and after 96 hours of immersion, from samples compacted to the water content of the OMP and with various energies of compaction $(10,25,55$ blows). This note showed that the two methods are appreciably the same ones. A CBR at four days of immersion recommended in the standards is justified.

\section{Acknowledgements}

The authors would like to acknowledge the Entreprise Jean Lefebvre sa for their guidance and valuable input in this research project.

\section{References}

[1] A. Remillon, "Les recherches routières entreprises en Afrique d'expresson française,” Application à la conception et au renforcement des chaussées économiques, ITBTP, 1967.

[2] M. D. Gidigasu, "Laterite soil engineering- Pedogenesis and Engineering Principles,” Elsevier Scientific Publishing Company Amsterdam, 1976.

[3] T. Aashto, "Standard Method of Test for Moisture-Density Relations of Soils Using a 2.5-kg (5.5-lb) Rammer and a 305-mm (12-in.) Drop,” In Standard Specifications for Transportation Materials and Methods of Sampling and Testing, American Association of State Highway and Transportation Officials (AASHTO), Washington DC, 1999.

[4] T. Aashto, "Standard Method of Test for the California Bearing Ratio,” In Standard Specifications for Transportation Materials and Methods of Sampling and Testing, American Association of State Highway and Transportation Officials (AASHTO), Washington DC, 1993.

[5] L. W. Ackroyd, "Engineering Classification of Some Western Nigerian Soils and Their Qualities in Road Building,” Road Research Laboratory, British, 1959.

[6] M. Fall, "Caractérisation et identification mécanique de trois graveleux latéritiques du Sénégal Occidental : Application au domaine routier," Thèse de Doctorat de l'INPL en Génie Civil et Minier de l’INPL-Nancy France, 1993, 277 pages, 2 annexes. 